\title{
Cultivo hidropônico de lisianto para flor de corte em sistema de fluxo laminar de nutrientes
}

\author{
Fernanda Alice Antonello Londero Backes ${ }^{(1)}$, José Geraldo Barbosa(2), Paulo Roberto Cecon ${ }^{(2)}$, \\ José Antonio Saraiva Grossi(2), Rogério Luiz Backes ${ }^{(3)}$ e Fernando Luiz Finger(2)
}

\begin{abstract}
(1)Universidade do Contestado, Rua Roberto Ehlke, no 80, Centro, CEP 89460-000 Canoinhas, SC. E-mail: fernanda@backes.com.br (2)Universidade Federal de Viçosa, Dep. de Fitotecnia, Av. P.H. Rolfs, s/no, CEP 36571-000 Viçosa, MG. E-mail: jgeraldo@ufv.br, cecon@dpi.ufv.br, jgrossi@ufv.br, ffinger@ufv.br (3)Empresa de Pesquisa Agropecuária e Extensão Rural de Santa Catarina, Estação Experimental de Canoinhas, CEP 89460-000 Canoinhas, SC. E-mail: backes@epagri.sc.gov.br
\end{abstract}

\begin{abstract}
Resumo - O objetivo deste trabalho foi avaliar as características produtivas e comerciais do cultivo de quatro cultivares de lisianto (Eustoma grandiflorum) em três soluções nutritivas em sistema de fluxo laminar de nutrientes (NFT). Utilizou-se o delineamento em blocos casualizados, em esquema fatorial 4x3, com três repetições. Os tratamentos foram compostos de quatro cultivares (Echo Champagne, Mariachi Pure White, Balboa Yellow e Ávila Blue Rim) e três soluções nutritivas (Teste, Steiner modificada e Barbosa). O sistema NFT é uma alternativa viável para o cultivo de lisianto nas soluções Barbosa e Teste. A cultivar Echo Champagne foi superior quanto ao ciclo, período em produção, altura da haste floral, número de folhas, diâmetro de botão e produção de massa fresca e seca, enquanto a cultivar Mariachi Pure White se destacou quanto ao período em produção. A cultivar Ávila Blue Rim apresentou maior período de produção, número de flores e produção de massa de matéria fresca e seca, enquanto a cultivar Balboa Yellow apresentou maior período em produção e diâmetro de botão.
\end{abstract}

Termos para indexação: Eustoma grandiflorum, floricultura, solução nutritiva, hidroponia.

\section{Hydroponic growth of lisianthus as cut flower under nutrient film technique}

\begin{abstract}
The objective of this work was to evaluate yield and commercial traits of lisianthus (Eustoma grandiflorum) flowers growth in nutrient film technique (NFT). The experimental design was in randomized blocks, in factorial scheme (4x3), with three replicates. The treatments were four cultivars (Echo Champagne, Mariachi Pure White, Balboa Yellow and Ávila Blue Rim) and three nutrient solutions (Test, modified Steiner and Barbosa). The NFT system is a feasible alternative for the growth of lisianthus in Barbosa and Test solutions. The cultivar Echo Champagne was superior for cycle, length of production, height of flower stem, number of leaves, diameter of the bud flower and fresh and dry weight production, while the cultivar Mariachi Pure White was superior for length of production. The cultivar Ávila Blue Rim showed good length of production, number of flowers and fresh and dry matter production, while the cultivar Balboa Yellow had long length of production and bud flower diameter.
\end{abstract}

Index terms: Eustoma grandiflorum, floriculture, nutrient solution, hydroponic.

\section{Introdução}

O mercado mundial de flores de corte se divide em países de alto consumo per capita por ano, da ordem de US\$100, contrastando com consumidores em potencial, como o Brasil, onde o consumo per capita por ano é US\$ 7 (Barbosa et al., 2003). O lisianto (Eustoma grandiflorum), pertencente à família das Gentianaceae, foi introduzido no mercado brasileiro no final da década de 80 e começou a se destacar economicamente a partir da década de 90, despertando interesse de produtores e consumidores (Salvador, 2000; Camargo et al., 2004).
A produção comercial de lisianto em sistema convencional tem sido limitada por viroses e patógenos do solo, como Fusarium solani, que ataca o sistema radicular e causa a podridão da haste e raízes, o que resulta no murchamento e secamento da planta. Entre os demais patógenos, destaca-se Phomopsis sp., que causa lesões nas hastes e folhas (Freitas et al., 1996; McGovern et al., 2000; Rivas et al., 2000; Wolcan et al., 2001). Essas doenças vêm limitando a produção da cultura, o que justifica o uso de novas técnicas, como o cultivo hidropônico, que pode proporcionar um meio de 
controle, principalmente das doenças em que o solo é a principal fonte de inóculo (Jensen, 1997).

Apesar de o cultivo hidropônico de flores ser recente, trabalhos têm sido conduzidos no Brasil (Barbosa et al., 1999, 2000; Pedrosa et al., 2001) com o intuito de gerar novas informações que potencializem as condições de cultivo em ambiente protegido.

Atualmente, o cultivo de flores em hidroponia tem sido explorado em países desenvolvidos, resultando em flores de melhor qualidade, principalmente quanto aos aspectos nutricionais e fitossanitários, com conseqüente aumento da vida pós-colheita das flores, que alcançam melhores preços durante a comercialização. No Brasil, a experiência de cultivo de flores sob hidroponia ainda é praticamente inexistente (Barbosa et al., 2003).

Em qualquer cultura, é essencial para o sucesso do cultivo hidropônico, além do conhecimento da composição da solução nutritiva a ser usada, o conhecimento sobre fatores ambientais (luminosidade, temperatura e umidade), época do ano (duração do período de luz), idade das plantas, espécie vegetal e a cultivar em produção.

Em cultivos hidropônicos, a composição da solução nutritiva se modifica à medida que a planta absorve seletivamente a água e os nutrientes (Carmello, 1996; Furlani, 1998; Andriolo, 1999). A solução nutritiva ideal pode ser sugerida a partir da determinação da composição química de plantas vigorosas da espécie com que se pretende trabalhar, em seus diversos estágios de crescimento e desenvolvimento, e deve ser confrontada com outras soluções indicadas para espécies e finalidades afins.

A busca de maior produtividade e a exigência do mercado quanto à qualidade, principalmente nutrição e sanidade, sugerem um mercado potencial para o cultivo hidropônico do lisianto, pela maior eficiência no uso da água e de nutrientes, aliada à menor incidência de doenças, observadas nesses sistemas. A técnica do fluxo laminar de nutrientes (NFT) tem-se mostrado eficiente no cultivo de várias espécies (Martinez, 2002), podendo, também, ser utilizada para o lisianto.

O objetivo deste trabalho foi avaliar características produtivas e comerciais do cultivo de quatro cultivares de lisianto em três soluções nutritivas, em sistema NFT.

\section{Material e Métodos}

O experimento foi conduzido em casa de vegetação com cobertura superior de filme de plástico de polietileno, com espessura de $150 \mu \mathrm{m}$, e laterais com filme de plástico e sombrite, $50 \%$ de luz (parte inferior até $1,5 \mathrm{~m}$ de altura a partir da base), no Setor de Olericultura do Departamento de Fitotecnia da Universidade Federal de Viçosa, Viçosa, MG, de 29 de julho a 22 de novembro de 2002.

As mudas de lisianto foram adquiridas do viveiro Isabel Yamagushi, Atibaia, SP. Quando apresentavam, aproximadamente, dois pares de folhas, efetuou-se o transplante para cubos de espuma fenólica de dimensão $5 \times 5 \times 3,8 \mathrm{~cm}$, que serviram de sustentação após as mudas serem colocadas nos perfis de crescimento. O transplantio das mudas para o sistema NFT foi realizado em 29 de julho de 2002.

$\mathrm{O}$ experimento foi conduzido em delineamento de blocos casualizados, em esquema fatorial $4 \times 3$, com 12 tratamentos e três repetições. Os tratamentos consistiram de quatro cultivares - Echo Champagne, cor champanhe, Mariachi Pure White, branca, Balboa Yellow, amarelo-clara e Ávila Blue Rim, branca com bordas azuis - e três soluções nutritivas - Steiner modificada (1984), Barbosa et al. (2000) e solução-teste.

Foram utilizadas 18 bancadas metálicas de ferro, de 2x0,8x0,8 m, com desnível de 2\%. Cada bancada sustentava quatro perfis de polipropileno, de tamanho médio (100 mm), espaçados em $20 \mathrm{~cm}$, perfurados a cada $25 \mathrm{~cm}$ com orifícios de $5 \mathrm{~cm}$ de diâmetro para a colocação das plantas. Em cada bancada, os dois perfis externos foram considerados bordadura e os dois internos representaram, cada um, uma unidade experimental (36 perfis). O espaçamento utilizado foi de $25 \mathrm{~cm}$ entre plantas nos perfis e $20 \mathrm{~cm}$ entre plantas de perfis distintos, com distribuição triangular, e cada perfil continha sete ou oito plantas, alternadamente, por parcela. $\mathrm{Na}$ avaliação, foram consideradas cinco plantas centrais do perfil, sendo as demais consideradas bordaduras.

As cultivares de lisianto utilizadas são as mais cultivadas pelos produtores por apresentarem flores dobradas de tamanho grande (6 a $8 \mathrm{~cm}$ de diâmetro, quando abertas), hastes firmes e colorações mais atraentes ao consumidor.

A solução de Steiner é indicada para o cultivo de espécies hortícolas para produção de flores e frutos; a solução Barbosa é indicada para o cultivo de crisântemo, 
enquanto a solução-teste foi obtida a partir de análises nutricionais prévias realizadas nas cultivares avaliadas. A composição dos macronutrientes $\mathrm{NO}_{3}{ }^{-}, \mathrm{NH}_{4}{ }^{+}$, $\mathrm{H}_{2} \mathrm{PO}_{4}^{-}, \mathrm{K}^{+}, \mathrm{Ca}^{2+}, \mathrm{Mg}^{2+} \mathrm{e} \mathrm{SO}_{4}^{2-}$ em mmol L-1 foi de 9, 3, 1 , 7, 4,5, 2 e 3,5 na solução Steiner (1984) modificada; 11,51, 2,88, 1,95, 12,92, 1,51, 1 e 0,5 na solução Barbosa et al. (2000) e de $12,8,3,2,0,7,6,6,1,5,2,7$ e 3,3 na solução-teste. A composição dos micronutrientes B, Cu, Fe, Mn, Mo e $\mathrm{Zn}$ em $\mu \mathrm{mol} \mathrm{L}^{-1}$ foi de $30,0,5,60,30,0,5$ e 1,5 em todas as soluções nutritivas.

As soluções nutritivas foram preparadas em caixas de cimento e amianto (1.000 L), impermeabilizadas com tinta betuminosa (Neutrol), utilizando-se água de poço artesiano, sendo o volume inicial de cada solução igual a $750 \mathrm{~L}$, e a distribuição até os canais de cultivo foi realizada por meio de canos de PVC. Um conjunto motobomba de 0,5 HP foi acoplado na parte inferior de cada reservatório para fornecer a solução nutritiva aos perfis de cultivo numa vazão de $2 \mathrm{~L}$ por minuto.

O cultivo do lisianto foi realizado em sistema de fluxo laminar de nutrientes (NFT). O fornecimento da solução nutritiva foi controlado por temporizador, programado para acionar o conjunto motobomba durante 15 minutos, com intervalo de 15 minutos, no período diurno (6h às 19h). A partir de 1ㅇ de outubro de 2002, o sistema motobomba passou a ser acionado também no período noturno, durante 15 minutos, com intervalo de 15 minutos, no período de $24 \mathrm{~h}$ até $1 \mathrm{~h}$.

Realizou-se, diariamente, a reposição do volume da solução com água e, na seqüência, procedeu-se à leitura de $\mathrm{pH}$ e da condutividade elétrica (CE). $\mathrm{O}$ pH foi corrigido, conforme a necessidade, para o intervalo de 5,5 a 6,5. A reposição de nutrientes foi realizada nas três soluções nutritivas em 20 de setembro de 2002, quando a $\mathrm{CE}$ atingiu $70 \%$ do valor inicial.

A poda acima do quinto par de folhas foi realizada em 20 de agosto de 2001, 24 dias após o transplante, nas cultivares Echo Champagne, Balboa Yellow e Ávila Blue Rim e em 29 de agosto, 33 dias após o transplante, na cultivar Mariachi Pure White. Para o tutoramento das plantas, utilizou-se malha de arame fino com barbante, sustentado com varas de bambu. Ao longo do cultivo, não foram observados ataques de pragas nem surgimento de sintomas de doenças.

Devido às altas temperaturas verificadas no início de outubro, no dia 11 de outubro de 2002, 76 dias após o transplante, colocou-se sombrite $(50 \%)$ na parte interna da casa de vegetação, sobre toda a área experimental, a uma altura de aproximadamente 2,3 m.
Os dados de temperatura diária e umidade relativa do ar, no período experimental, foram registrados diariamente em um termoigrógrafo instalado no centro da casa de vegetação, a $1 \mathrm{~m}$ de altura, e as temperaturas máximas e mínimas foram, em média, de 40 e $12^{\circ} \mathrm{C}$, respectivamente, e umidade relativa de $70 \%$.

A colheita das hastes se iniciou em 10 de outubro de 2002, quando as primeiras plantas apresentavam um botão com sépalas totalmente abertas e pétalas em início de abertura, realizando-se cortes rentes à base da planta.

As seguintes características foram avaliadas: ciclo da planta (número de dias entre o transplante e o início da colheita) (Halevy \& Kofranek, 1984; Tjia \& Shechan, 1986), período em produção (número de dias entre o início e o final da colheita), altura da haste floral $(\mathrm{cm})$, número de hastes por planta, número de folhas por planta, número de flores por planta, diâmetro dos botões $(\mathrm{cm})$, comprimento do sistema radicular $(\mathrm{cm})$, massa de matéria fresca da parte aérea (g por planta), massa de matéria seca de caule (g por planta), massa de matéria seca das folhas ( $g$ por planta), massa de matéria seca das flores (g por planta) e massa de matéria seca da parte aérea (g por planta).

Os resultados foram submetidos à análise da variância e as médias comparadas pelo teste de Tukey, a 5\% de probabilidade. A análise estatística foi realizada com o auxílio do SAEG (Universidade Federal de Viçosa, 2007).

\section{Resultados e Discussão}

Foram observadas interações entre cultivares e soluções apenas quanto à variável massa de matéria seca de flor por planta, cujo coeficiente de variação foi $14,51 \%$.

A solução Barbosa et al. (2000) e a solução-teste proporcionaram valores superiores das características associadas ao crescimento e ao acúmulo de massa do que a solução Steiner modificada (Tabela 1), provavelmente devido à maior concentração de nitrogênio $\left(\mathrm{NO}_{3}{ }^{-} / \mathrm{NH}_{4}{ }^{+}\right)$. A cultivar Ávila Blue Rim apresentou ciclo mais curto que as demais, com colheita das hastes iniciada 76,33 dias após o transplante, e apresentou resultados satisfatórios quanto à altura da haste floral e número de flores por planta, sendo essas características importantes na produção e na comercialização de flores de corte (Tabela 2).

Os resultados observados para ciclo (Tabela 2), entre 76 e 87 dias, são satisfatórios. De acordo com 
Griesbach et al. (1998), o ciclo de cultivo do lisianto é de quatro a seis meses, e varia em virtude do ambiente e da cultivar. Na cultivar Lisianthus russellianus, cultivada em solo, Tjia \& Shechan (1986) observaram ciclo médio de 112 e 114 dias, no entanto os autores não relatam as cultivares avaliadas. A cultivar Fuji Pink, cultivada em lã de rocha, apresentou diferentes ciclos em virtude da data do transplante: 87 dias quando transplantada em maio, e de 120 dias quando transplantada em fevereiro (Labeke et al., 1995). Camargo et al. (2004) verificaram ciclo de 120 dias, após o transplantio, com a cultivar Echo cultivada em solo.

Não houve diferença significativa entre as cultivares de lisianto para período em produção, que variou de 26 a 32 dias, o que possibilita boa flexibilidade de comercialização pelo produtor. A altura da haste floral da cultivar Echo Champagne foi superior à das cultivares Balboa Yellow e Mariachi Pure White (Tabela 2). No entanto, no Brasil, ainda não existem padrões de classificação para a comercialização do lisianto como flor de corte. Halevy \& Kofranek (1984) obtiveram médias de altura de haste de lisianto como flor de corte nas cores Blue e White, de 34 e $59 \mathrm{~cm}$, respectivamente. No Brasil, Camargo et al. (2004) observaram comprimento de hastes de 90,5 cm com a cultivar Echo,

Tabela 1. Altura de haste floral (AH), massa de matéria fresca da parte aérea (MFPA), massa de matéria seca de caule (MSCP), massa de matéria seca de folha (MSFP) e massa de matéria seca da parte aérea (MSPA) de cultivares de lisianto (média geral das cultivares) cultivadas em hidroponia sob três soluções nutritivas ${ }^{(1)}$.

\begin{tabular}{|c|c|c|c|c|c|}
\hline \multirow[t]{2}{*}{ Soluções } & \multirow{2}{*}{$\begin{array}{c}\mathrm{AH} \\
(\mathrm{cm})\end{array}$} & MFPA & MSCP & MSFP & MSPA \\
\hline & & \multicolumn{4}{|c|}{--- (g por planta) -- } \\
\hline Teste & $53,75 \mathrm{a}$ & $129,54 a$ & $38,07 \mathrm{a}$ & $6,48 \mathrm{ab}$ & $47,35 \mathrm{a}$ \\
\hline Steiner & $46,02 b$ & $105,28 \mathrm{~b}$ & $29,78 b$ & $5,73 b$ & $38,08 \mathrm{~b}$ \\
\hline Barbosa et al. & $54,60 \mathrm{a}$ & $138,96 \mathrm{a}$ & $43,37 \mathrm{a}$ & $6,80 \mathrm{a}$ & $53,16 \mathrm{a}$ \\
\hline $\mathrm{CV}(\%)$ & 7,92 & 15,40 & 8,52 & 14,68 & 16,20 \\
\hline
\end{tabular}

(1) Médias seguidas pela mesma letra não diferem entre si pelo teste Tukey, a $5 \%$ de probabilidade. cultivada no solo. É provável que essa variação tenha ocorrido em razão das diferenças entre as cultivares e, principalmente, entre as condições ambientais, as quais afetam o desenvolvimento da cultura.

O menor número de folhas por planta foi observado na cultivar Mariachi Pure White, que não diferiu significativamente do obtido nas cultivares Balboa Yellow e Ávila Blue Rim. A cultivar Echo Champagne apresentou maior número de folhas por planta, em relação à cultivar Mariachi Pure White, porém não diferiu de Balboa Yellow e Ávila Blue Rim (Tabela 2). Camargo et al. (2004) consideram importante o número de folhas nas hastes de lisianto, tanto pelo aspecto visual quanto pela contribuição para a massa de matéria seca de caule. Os autores obtiveram, aos 120 dias após o transplantio da cultivar Echo, número médio de 76 folhas por haste floral.

Quanto ao número de flores por planta, a cultivar Ávila Blue Rim foi superior (30,13 flores por planta) à cultivar Balboa Yellow (22,5 flores por planta), e não diferiu significativamente das cultivares Echo Champagne e Mariachi Pure White, com 26,5 e 25,8 flores por planta, respectivamente (Tabela 2). As elevadas temperaturas na casa de vegetação, em torno de $40^{\circ} \mathrm{C}$, em outubro, podem ter afetado a produção de flores. Segundo Corr \& Katz (1997), temperaturas superiores a $25^{\circ} \mathrm{C}$ afetam a produção e a qualidade de hastes florais de lisianto. A cultivar Balboa Yellow, mais sensível, apresentou, nessa ocasião, folhas mais jovens e botões em formação secos. $\mathrm{O}$ uso de sombrite minimizou esse efeito, o que favoreceu a maior produção de flores nas cultivares Ávila Blue Rim, Echo Champagne e Mariachi Pure White. Halevy \& Kofranek (1984), na avaliação de duas cultivares de lisianto, constataram produção média de 18,56 e 36,36 flores por planta.

As cultivares Balboa Yellow e Echo Champagne não diferiram entre si quanto ao diâmetro de botão e foram superiores às cultivares Ávila Blue Rim e Mariachi Pure White (Tabela 2). Essa característica não é comumente avaliada em trabalhos realizados com lisianto, pois o ponto de colheita usualmente considerado é verificado quando

Tabela 2. Ciclo, período em produção (PP), altura da haste floral (AH), número de folhas por planta (NFP), número de flores por planta (NFLP) e diâmetro de botão (DB), de cultivares de lisianto cultivadas em hidroponia(1).

\begin{tabular}{|c|c|c|c|c|c|c|}
\hline Cultivar & $\begin{array}{l}\text { Ciclo } \\
-\end{array}$ & $\begin{array}{c}\text { PP } \\
-\end{array}$ & $\begin{array}{r}\mathrm{AH} \\
(\mathrm{cm})\end{array}$ & NFP & NFLP & $\begin{array}{c}\mathrm{DB} \\
(\mathrm{cm})\end{array}$ \\
\hline Echo Champagne & $87,22 \mathrm{a}$ & $26,67 \mathrm{a}$ & $57,19 a$ & $117,66 \mathrm{a}$ & $26,62 a b$ & $1,69 \mathrm{a}$ \\
\hline Mariachi Pure White & $86,67 \mathrm{ab}$ & $26,44 \mathrm{a}$ & $42,22 \mathrm{c}$ & $88,43 b$ & $25,82 \mathrm{ab}$ & $1,36 \mathrm{c}$ \\
\hline Balboa Yellow & $83,11 \mathrm{~b}$ & $30,00 \mathrm{a}$ & $51,19 \mathrm{~b}$ & $103,42 \mathrm{ab}$ & $22,52 b$ & $1,71 \mathrm{a}$ \\
\hline Ávila Blue Rim & $76,33 \mathrm{c}$ & $32,22 \mathrm{a}$ & $55,22 \mathrm{ab}$ & $105,82 \mathrm{ab}$ & $30,13 \mathrm{a}$ & $1,52 \mathrm{~b}$ \\
\hline $\mathrm{CV}(\%)$ & 3,62 & 15,36 & 7,92 & 14,50 & 17,54 & 4,44 \\
\hline
\end{tabular}

${ }^{(1)}$ Médias seguidas pela mesma letra não diferem entre si pelo teste Tukey, a $5 \%$ de probabilidade. 
pelo menos uma flor está completamente aberta (Halevy \& Kofranek, 1984). No entanto, a colheita dos botões com as sépalas totalmente abertas e as pétalas em início de abertura torna-se viável, pois pode prolongar a vida útil das flores após a colheita.

O comprimento do sistema radicular da cultivar Echo Champagne foi superior ao das cultivares Mariachi Pure White e Ávila Blue Rim e não diferiu significativamente da cultivar Balboa Yellow (Tabela 3).

As cultivares avaliadas apresentaram o mesmo comportamento quanto à massa de matéria fresca e seca da parte aérea e à massa de matéria seca de caule por planta (Tabela 3). As cultivares Echo Champagne e Ávila Blue Rim apresentaram produção de massa de matéria fresca e seca da parte aérea e massa de matéria seca de caule superior à cultivar Mariachi Pure White e não diferiram significativamente da cultivar Balboa Yellow. A produção de folhas foi maior nessas cultivares (Tabela 2), o que possibilitou maior produção de massa de matéria fresca e seca da parte aérea das plantas. Harbaugh \& Woltz (1991), ao avaliar a cultivar Saga Purple, observaram que a massa de matéria fresca da parte aérea foi de $68,8 \mathrm{~g}$, valor abaixo do encontrado neste trabalho. Da mesma forma, Camargo et al. (2004), na avaliação da cultivar Echo, verificaram 28,4 g de massa de matéria seca da parte aérea por planta, valor inferior ao observado neste trabalho.

Na solução-teste, melhor resposta quanto à produção de massa de matéria seca de flor por planta foi obtida na cultivar Ávila Blue Rim em relação à cultivar Balboa Yellow. Na solução Steiner modificada, as quatro cultivares apresentaram o mesmo resultado para esta variável, pois não houve diferença significativa entre as mesmas. Quanto à solução proposta por Barbosa et al. (2000), a maior produção de massa de matéria seca de flor por planta ocorreu na cultivar Ávila Blue Rim (Tabela 4).

Tabela 3. Comprimento do sistema radicular (CR), massa de matéria fresca da parte aérea (MFPA), massa de matéria seca de caule (MSCP) e massa de matéria seca da parte aérea (MSPA), de cultivares de lisianto cultivadas em hidroponia ${ }^{(1)}$.

\begin{tabular}{lcccc}
\hline Cultivar & $\begin{array}{c}\text { CR } \\
(\mathrm{cm})\end{array}$ & \multicolumn{1}{c}{ MFPA } & MSCP & MSPA \\
\hline Echo Champagne & $32,12 \mathrm{a}$ & $139,96 \mathrm{a}$ & $40,52 \mathrm{a}$ & $50,13 \mathrm{a}$ \\
Mariachi Pure White & $27,68 \mathrm{~b}$ & $103,23 \mathrm{~b}$ & $31,20 \mathrm{~b}$ & $39,23 \mathrm{~b}$ \\
Balboa Yellow & $29,61 \mathrm{ab}$ & $124,32 \mathrm{ab}$ & $35,67 \mathrm{ab}$ & $44,75 \mathrm{ab}$ \\
Ávila Blue Rim & $27,24 \mathrm{~b}$ & $130,87 \mathrm{a}$ & $40,89 \mathrm{a}$ & $50,68 \mathrm{a}$ \\
\hline CV $(\%)$ & 8,99 & 15,40 & 16,98 & 16,20 \\
\hline
\end{tabular}

(1)Médias seguidas pela mesma letra não diferem entre si pelo teste Tukey, a $5 \%$ de probabilidade.
Tabela 4. Massa de matéria seca de flor (g por planta), de cultivares de lisianto cultivadas em hidroponia, sob três soluções nutritivas ${ }^{(1)}$.

\begin{tabular}{llll}
\hline Cultivares & \multicolumn{3}{c}{ Soluções } \\
\cline { 2 - 4 } & \multicolumn{1}{c}{ Teste } & Steiner & Barbosa \\
\hline Echo Champagne & $2,80 \mathrm{ABa}$ & $2,55 \mathrm{Aa}$ & $3,22 \mathrm{ABa}$ \\
Mariachi Pure White & $2,97 \mathrm{ABa}$ & $2,23 \mathrm{Aab}$ & $1,91 \mathrm{Cb}$ \\
Balboa Yellow & $2,22 \mathrm{Ba}$ & $2,37 \mathrm{Aa}$ & $2,76 \mathrm{BCa}$ \\
Ávila Blue Rim & $3,23 \mathrm{Aab}$ & $3,13 \mathrm{Ab}$ & $4,05 \mathrm{Aa}$ \\
\hline
\end{tabular}

(1)Médias seguidas pela mesma letra, maiúscula na coluna e minúscula na linha, não diferem entre si pelo teste Tukey, a 5\% de probabilidade.

Nas cultivares Echo Champagne e Balboa Yellow, a produção de massa de matéria seca de flor por planta foi equivalente nas três soluções nutritivas estudadas. As cultivares Mariachi Pure White e Ávila Blue Rim responderam diferentemente às soluções nutritivas. Na cultivar Mariachi Pure White, a maior produção de massa de matéria seca de flor foi observada quando se utilizou a solução-teste, enquanto na cultivar Ávila Blue Rim, a maior produção de massa de matéria seca de flor foi obtida quando se utilizou a solução proposta por Barbosa et al. (2000) (Tabela 4).

\section{Conclusões}

1. O sistema hidropônico de fluxo laminar de nutrientes é uma alternativa viável para o cultivo de lisianto como flor de corte.

2. A solução nutritiva proposta por Barbosa et al. e a solução-teste são satisfatórias para o cultivo de lisianto no sistema de fluxo laminar de nutrientes.

3. As cultivares Echo Champagne e Ávila Blue Rim apresentam características produtivas e comerciais melhores sob cultivo no sistema de fluxo laminar de nutrientes.

\section{Referências}

ANDRIOLO, J.L. Fisiologia das culturas protegidas. Santa Maria: UFSM, 1999. 142p.

BARBOSA, J.G.; KAMPF, A.N.; MARTINEZ, H.E.P.; KOLLER, O.C.; BOHNEN, H. Chrysanthemum cultivation in expanded clay. I. Effect of the nitrogen-phosphorus-potassium ratio in the nutrient solution. Journal of Plant Nutrition, v.23, p.1327-1336, 2000.

BARBOSA, J.G; MARTINEZ, H.E.P.; KAMPF, A.N. Acúmulo de macronutrientes em plantas de crisântemo sob cultivo hidropônico em argila expandida para flor-de-corte. Pesquisa Agropecuária Brasileira, v.34, p.593-601, 1999.

BARBOSA, J.G.; MARTINEZ, H.E.P.; KAMPF, A.N.; BACKES, F.A.A.L.; BARBOSA, M.S. Cultivo hidropônico do crisântemo. In: BARBOSA, J.G. Crisântemos: produção de mudas, cultivo para corte de flor, cultivo em vaso e cultivo hidropônico. Viçosa: Aprenda Fácil, 2003. p.179-215. 
CAMARGO, M.S.; SHIMIZU, L.K.; SAITO, M.A.; KAMEOKA, C.H.; MELLO, S.C.; CARMELLO, Q.A.C. Crescimento e absorção de nutrientes pelo lisianthus (Eustoma grandiflorum) cultivado em solo. Horticultura Brasileira, v.22, p.143-146, 2004.

CARMELLO, Q.A.C. Cultivo hidropônico de plantas. Piracicaba: Esalq, 1996. 43p.

CORR, B.; KATZ, P. A grower's guide to lisianthus production. Floraculture International, v.7, p.16-20, 1997.

FREITAS, C.; KITAJIMA, E.W.; REZENDE, J.A.M. First report of tobacco streak virus on lisianthus in Brazil. Plant Disease, v.80, p.1080, 1996.

FURLANI, P.R. Instruções para o cultivo de hortaliças de folhas pela técnica de hidroponia NFT. Campinas: IAC, 1998. 30p. (Documentos IAC, 168).

GRIESBACH, R.J.; SEMESIUK, P.; ROH, M.; LAWSON, R.H. Tissue culture in the improvement of Eustoma. HortScience, v.23, p.790-791, 1988.

HALEVY, A.H.; KOFRANEK, A.M. Evaluation of lisianthus as a new flower crop. HortScience, v.19, p.845-847, 1984.

HARBAUGH, B.K.; WOLTZ, S.S. Eustoma quality is adversely affected by low $\mathrm{pH}$ of root medium. HortScience, v.26, p.12791280, 1991.

JENSEN, M.H. Principales sistemas hidropónicos: principios, ventajas y desventajas. In: CONFERENCIA INTERNATIONAL DE HIDROPONIA COMERCIAL, Lima, 1997. Anais. Lima: UNALM, 1997. p.35-48.
LABEKE, M.C. van; DAMBRE, P.; SCHREVENS, E.; RIJCK, G. Optimisation of the nutrient solution for Eustoma grandiflorum in soilless culture. Acta Horticulturae, v.401, p.401-408, 1995.

MARTINEZ, H.E.P. O uso do cultivo hidropônico de plantas em pesquisa. Viçosa: UFV, 2002. 61p. (Cadernos Didáticos 1).

McGOVERN, R.J.; SEIJO, T.E.; HARBAUGH, B.K. Outbreaks of stem and leaf blight of Eustoma grandiflorum caused by Phomopsis sp. in Florida. Plant Disease, v.84, p.491, 2000.

PEDROSA, M.W.; BARBOSA, J.G.; MARTINEZ, H.E.P.; CARDOSO, A.A. Avaliação do crescimento de Gypsophila paniculata L. em solução hidropônica. Revista Brasileira de Horticultura Ornamental, v.7, p.49-56, 2001.

RIVAS, E.B.; GALLETI, S.R.; DUARTE, L.M.L.; SEABRA, P.V.; ALEXANDRE, M.A.V. Virus and phytoplasm diseases of lisianthus. Summa Phytopathologica, v.26, p.257-262, 2000.

SALVADOR, E.D. Caracterização física e formulação de substratos para o cultivo de algumas ornamentais. 2000. 148p. Tese (Doutorado) - Universidade de São Paulo, Piracicaba.

STEINER, A.A. The universal solution. In: INTERNATIONAL CONGRESS ON SOILLESS CULTURE, 6., 1984. Proceedings. Lunteren: ISOSC, 1984. p.633-649.

TJIA, B.; SHECHAN, T.J. Chemical height control of Lisianthus russellianus. HortScience, v.21, p.147-148, 1986.

UNIVERSIDADE FEDERAL DE VIÇOSA. SAEG: sistema para análises estatísticas e genéticas. Versão 9.1. Viçosa: Fundação Arthur Bernardes, 2007.

WOLCAN, S.; LORI, G.; RONCO, L. First report of Fusarium solani causing stunt on lisianthus. Plant Disease, v.85, p.443, 2001. 